\title{
Multi-Functionality of Metaphor in Newspaper Discourse
}

\begin{abstract}
This paper investigates cognitive and social functions that metaphor fulfils in newspaper discourse on natural catastrophes, aiming to reveal multi-functionality of figurative language. The analysis shows that natural phenomena are metaphorically constructed as ANIMALS, MONSTERS and WAR. These metaphor themes function as a conceptual tool and an effective ideological weapon. They simplify reality, hide politico-economic and social conditions, bipolarize the world, dramatize stories by appealing to readers' emotions, and create feelings of community and belonging.

The analysis draws upon critical discourse analysis and the cognitive theory of metaphor, as introduced by Lakoff and Johnson (1980). The corpus used in the analysis consists of articles on the 2004 Indian Ocean tsunami and 2005 Hurricane Katrina, which are compiled from The Globe and Mail (2004; 2005), a Canadian national daily newspaper, and The New York Times (2004; 2005), an American national daily newspaper.
\end{abstract}

\section{Key words}

Metaphor; multi-functionality; natural catastrophes; newspaper discourse; ideology

\section{Introduction}

The study of metaphor has been of interest to scholars since the Ancient Greece. Two influential theories of metaphor developed in the past: a comparison theory and a substitution theory. The origins of the comparison theory can be traced back to Aristotle ( $4^{\text {th }}$ century $\mathrm{BC}$ ), who viewed metaphors as implicit comparisons, based on the principle of analogy (Ortony 1979: 3). The comparison theory 
thus treats metaphor as a condensed simile and a primarily ornamental feature of speech (Martin and Harré 1982: 90). The key characteristic of the substitution theory is the belief that "metaphor is a way of saying what could be said literally" (Martin and Harré 1982: 90) and therefore merely substitutes literal speech. Both the comparison and the substitution theory share the conviction that literal language is natural while figurative language is deviant.

The $20^{\text {th }}$ century brought a change in the view of metaphor, with prominent Anglo-American philosophers and literary critics I. A. Richards and Max Black recognizing that "metaphor can lead to the construction of new meanings by bringing together different ideas and systems of knowledge" (Semino 2008: 9). Metaphor gradually started to be considered as a feature of everyday language, not just poetic discourse. The most significant turn in the study of metaphor came in 1980 when Lakoff and Johnson's influential work Metaphors We Live By was published. This work laid the foundation to the cognitive theory of metaphor, according to which "our ordinary conceptual system, in terms of which we both think and act, is fundamentally metaphorical in nature" (Lakoff and Johnson 1980: 3; see also Lakoff and Turner 1989; Gibbs 1994; Lakoff and Johnson 1999; Kövecses 2010). Thus, metaphor ceases to be seen just as a matter of language and comes to be viewed as a matter of thought as well. According to cognitive theorists, metaphor plays a key role in our conceptualization of abstract, unfamiliar and poorly delineated areas of experience (Thornborrow 1993; Kövecses 2000; Hiraga 2005; Goalty 2007; Semino 2008). Recently, the focus has shifted to the investigation of ideological effects of metaphor, including studies on political discourse (Chilton 1996; Musolff 2004; Charteris-Black 2005), immigrants (Santa Ana 1999; El Refaie 2001), the Iraq war (Lule 2004) and business discourse (Koller 2004).

Inspired by the work of cognitive theorists and researchers of the ideological working of metaphor, this paper aims to reveal multi-functionality of metaphor on the analysis of concrete linguistic material. The focus is on social and cognitive functions that metaphor fulfils in newspaper articles on natural catastrophes. More specifically, it asks whether metaphors employed in newspaper discourse on natural catastrophes are just a matter of language or work also as a conceptual tool which helps readers to make sense of the events. It investigates the ideological aspects of the metaphor themes present in the articles and points out other functions that metaphor serves. On the whole, the goal is to show that because of multi-functionality, metaphor is an 'all-in-one' discursive device, which makes it a very effective linguistic tool to be used in newspapers.

The methodology employed in the paper mainly draws upon two approaches of linguistics: the cognitive theory of metaphor (see above) and critical discourse analysis, the goal of which is to investigate the link between language, power and ideology (Fairclough 1995; Weiss and Wodak 2003; Wodak 2006; van Dijk 2008; Wodak and Meyer 2009).

The body of data used in the analysis consists of articles on two major natural disasters that happened in the last decade: the 2004 Indian Ocean tsunami and 2005 Hurricane Katrina. As this paper is a part of my dissertation thesis, which 
focuses on the investigation of the way newspapers deal with the tension between natural catastrophes and Enlightenment ideology of domination of mankind over the natural world prevalent in Western thinking, two newspapers considered to be representative of Western English-speaking countries have been selected as sources: The Globe and Mail, a Canadian national daily newspaper, and The New York Times, an American national daily newspaper. The number of collected newspaper articles is 15 per newspaper for each catastrophe, which makes the total number of articles gathered in the corpus 60 . The articles cover the time span of two weeks since the disaster occurred, i.e. December 26, 2004 - January 8, 2005 for the Indian Ocean tsunami, and August 29, 2005 - September 11, 2005 for Hurricane Katrina.

The next section, which is analytical, introduces major metaphor themes employed by the newspapers in their representation of the tsunami and the hurricane and the lexical and syntactical realizations of these metaphor themes. This is followed by a section which discusses multiple social and cognitive functions that the metaphor serves. The paper is concluded with a few summarizing comments.

\section{Analysis}

There can be detected three major metaphor themes which are repeatedly drawn upon in newspaper discourse on both the tsunami and the hurricane: representation of the natural phenomenon as an ANIMATE BEING, a MONSTER and WAR. These metaphorical themes are systematically realized by various lexical and syntactical devices. They thus form basic frameworks by which natural catastrophes are represented in the newspapers.

One of the main metaphor themes employed in the newspapers is the portrayal of the tsunami and the hurricane as ANIMATE BEINGS. It is realized by a number of linguistic devices. Firstly, the natural phenomena are portrayed as having an animal body. Apart from the centre of a hurricane being referred to as an eye, the natural phenomenon is portrayed as having teeth:

(1) The hurricane $[\ldots]$ continued to putter along into adjoining states, though its teeth were gone. (The New York Times, 31 Aug 2005)

When describing actions of the tsunami and the hurricane, the articles use verbs the denotative meaning of which implies performance by parts of an animal body: the sea swallows and sucks people (uses a mouth, a tongue and lips), the hurricane pummels (hits with fists) and wind kicks up (movement with feet). The hurricane is further personified by being given a human name. Such a characteristic, which is missing in reference to the tsunami, provides the hurricane with a unique identity and portrays it as though it is a being of a sort.

Another characteristic that both the tsunami and the hurricane share with animate beings is the sound that they make: they roar and howl. These sounds have 
rather negative connotations and portray the natural phenomena as wild. Wildness is also implied in the phrase savage winds, which uses an adjective commonly used to talk about animals that are wild and fierce. What is more, emotions are ascribed to the natural phenomena:

(2) The waterline was dipping off to the sides and rising furiously in the middle. (The New York Times, 31 Dec 2004)

(3) "I want to send pictures back home to the United States so that my family and friends can see the wrath of Mother Nature," he said. (The Globe and Mail, 4 Jan 2005)

(4) This hurricane killed dozens and cut a swath of fury across the U.S. South. (The Globe and Mail, 30 Aug 2005)

The tsunami and the hurricane are thus characterized as being extremely angry. The reason for such an emotional state is left unspecified; yet, the employment of the word wrath implies that the motive of the actions of nature is one of vengeance and punishment.

The metaphor theme of ANIMATION is not realized just lexically but also syntactically. One of the syntactic devices that imply animation is the use of a possessive genitive instead of an 'of-phrase' when referring to the tsunami and the hurricane, as in the tsunami's power and Katrina's wake. More importantly, animation is implicitly established in the transitivity pattern of sentences. As pointed out by Fowler, "transitivity is the foundation of representation: it is the way the clause is used to analyze events and situations as being of certain types" (1991: 70). Basically, the argument is that agency is indexed through syntax. The majority of the sentences referring to the tsunami and the hurricane are in an active voice of the following type:

\begin{tabular}{|l|l|l|l|}
\hline $\begin{array}{l}\text { The natural } \\
\text { phenomenon }\end{array}$ & verbal group & (nominal group) & $\begin{array}{l}\text { (adverbial group or } \\
\text { prepositional phrase). }\end{array}$ \\
\hline Actor & Material process & Patient & Circumstances \\
\hline
\end{tabular}

(5) Raging waters swept villagers out to sea and tore children from their parents' arms. (The Globe and Mail, 27 Dec 2004)

(6) Hurricane Katrina pounded the Gulf Coast with devastating force at daybreak on Monday. (The New York Times, 30 Aug 2005)

The role of the patient is mostly performed by people or objects. Verbs commonly used in the sentences of the type mentioned above are: batter, push, strike, lash, hit, smash and sweep. From a semantic point of view, all of these verbs demand force. The wind and water occupy the role of an agent, who is in control of and responsible for the actions. The transitivity pattern of the sentences thus implies that the natural phenomena act with force and volition, which helps to establish the tsunami and the hurricane as animate, implying that they act on purpose. 
The second metaphor theme is a demonizing theme - it portrays the natural phenomenon as a MONSTER, i.e. a large, powerful, frightening and violent animate being. There can be found a number of references in the articles which directly and explicitly portray the tsunami and the hurricane as a monster:

(7) The deadly wave was unimaginably big, stretching to the horizons, and it struck suddenly, looming up with a roar like a monster from the deep. (The New York Times, 27 Dec 2004)

(8) Officials in Louisiana, Mississippi and Alabama said it was too early to calculate the number of lives lost in the monster storm. (The Globe and Mail, 31 Aug 2005)

Apart from explicit expressions, the newspapers draw upon a number of other discursive devices, mainly emotionally colored lexis and hyperbole, to convey the MONSTER metaphor. Referring to the size of the natural phenomenon, the articles are replete with hyperbolic adjectives, such as massive, colossal, huge, giant, mammoth and gargantuan. The portrayal of the natural phenomenon as having abnormal physical power is realized through the verbs denoting material processes demanding a great force, such as batter, smash and ravage, which also imply violence of nature. Apart from these, the extraordinary power of the tsunami and the hurricane is conveyed through the connotations of the verbs used in the sentences of the following type:

(9) It picked up cars and swept them hundreds of yards inland. (The New York Times, 31 Dec 2004)

(10) The rising flow pushed them upward and pinned them against the ceiling and the top of the door frame. (The Globe and Mail, 27 Dec 2004)

(11) Modest bungalows and working-class apartment buildings were thrashed, torn open like cellophane bags. (The New York Times, 31 Aug 2005)

Our common associations with the material processes pick up, sweep, pin and tear open are: the actor is a human being and the object of the action is something relatively small. The employment of the verbs in the sentences above, on one hand, implies animation of the natural phenomenon, and, on the other hand, initiates a comparison of a small object with cars in the first case, people in the second case, and bungalows and apartment buildings in the third case. Such a comparison leads to the conclusion that something which picks up and sweeps cars, pins people against the ceiling, and tears open bungalows and apartment buildings must be extraordinarily powerful.The effect of these sentences is based on the contrast between what commonly stands for the object of the actions - something small - and what stands for the object when referring to the actions of the tsunami and the hurricane - something heavy and big. These representations imply that the natural phenomenon is more powerful than people. The Western Enlightenment ideology of domination of people over nature is thus disrupted. 
Another characteristic that is attributed to the tsunami and the hurricane by the newspapers is cruelty. The articles explicitly refer to the natural phenomenon as merciless and brutal, portraying it thus as having no sympathy with people. Such a representation is even intensified by the employment of the metaphor themes of FIGHT and WAR.

The metaphor themes of FIGHT and WAR are often realized by explicit comparisons in similes, as in it looks like we've been nuked or reporters likened it to war zones. Apart from similes, a number of other references to war and fight occur in news discourse, for instance, the depiction of the hurricane as pummeling, i.e. fighting with fits, the description of the landscape as a bombed-out landscape, and the portrayal of the landfall of the hurricane as the onslaught from Katrina. The natural phenomenon is seen as acting with volition, aiming to physically set upon people. Such a view is also conveyed in the following two examples:

(12) The water separated, then it attacked. (The New York Times, 31 Dec 2004)

(13) The hurricane targeted the heart of U.S. oil. (The Globe and Mail, 29 Aug 2005)

Instead of revealing that the waves and the wind move because of geophysical forces, the newspapers portray the natural phenomena as having a desired goal, a target - to hurt and kill people, and cause damage to their property.

To intensify the negative portrayal of the tsunami and the hurricane even more, newspaper discourse constructs the notion of the natural phenomena as punishing people, which is explicitly expressed in the following sentences:

(14) Our mother has punished us. (The New York Times, 5 Jan 2005)

(15) The storm was potent enough to rank as one of the most punishing hurricanes ever to hit the United States. (The New York Times, 30 Aug 2005)

What it is that people are punished for is, though, left unspecified. In effect, the 'punishing' theme, on one hand, evokes the feeling of guilt in people, and on the other hand, portrays the natural phenomena as malicious. To sum up, the metaphor themes of FIGHT and WAR construct the tsunami and the hurricane as evil and a people's foe.

\section{Discussion}

Firstly, the focus is put on the investigation of cognitive functions performed by the metaphor themes presented in the analytical part. The analysis of both newspapers reveals the pervasiveness of figurative language in newspaper discourse, which proves that metaphor is not just an ornamental device of poetic discourses but rather a common feature of everyday, ordinary discourses. Newspaper articles repeatedly draw upon all three metaphor themes to build a coherent picture 
of natural catastrophes. The metaphors are thus not just a matter of language but form frames in which newspapers conceptualize the events.

As pointed out by cognitive theorists, metaphor is a mapping of structure from a source conceptual domain to a target conceptual domain based on the correlation of our experience in these two domains and our ability to structure one concept in terms of the other (Dobrovol'skij and Piirainen 2005). Therefore, metaphor enables people to make sense of a complex and unfamiliar aspect of reality, like natural catastrophes, in terms of a more concrete, clear and familiar phenomenon, such as animate beings, monsters and war (cf. Thornborrow 1993; El Refaie 2001; Hiraga 2005). More specifically, the metaphor theme of ANIMATION involves personification, which allows us to comprehend a wide variety of experiences with nonhuman entities in terms of human motivations, characteristics, and activities which we come in terms with every day (Lakoff and Johnson 1980). At the same time, newspapers help readers to understand natural catastrophes, events which most people have never experienced and therefore are not easily imaginable, by drawing upon MONSTER and WAR themes, phenomena which readers are more familiar with because of cultural models and artifacts, such as myths, books and films. Metaphor thus brings natural catastrophes nearer to people's common experience.

A 'side-effect' of metaphor functioning as a cognitive tool, i.e. helping people to comprehend complex phenomena, is that it simplifies reality. As pointed out by Semino (2008: 86), metaphor foregrounds only some aspects of the concept while downplays others. It is especially the connotations held by the source domain and the associations which we have built up with it that are transferred to the target domain. In the case of natural catastrophes, the employment of the metaphor themes of a wild ANIMAL, a MONSTER and WAR highlights just negative aspects of natural phenomena in spite of the fact that natural catastrophes are a complex issue. For instance, positive contributions of hurricanes, such as playing "supporting role in the regional ecology of the coastal zone" and having positive influence on agriculture (Simpson and Riehl 1981: 17), are hidden and made invisible in the process of metaphor working. The metaphor themes provide a rather black-and-white portrayal of reality. They categorize natural catastrophes so that they fit into the categorical system which we are familiar with and thus help us to deal with the 'unknown'. As Radman (1997: 167) points out, metaphor "represents a cognitive shift from initial puzzlement to an articulated pattern". The human tendency to bring order to reality and gain 'imaginary' control over it is satisfied by metaphor. Simplification therefore represents an important cognitive function of metaphor that allows people to grasp reality.

The paper now moves to the discussion of the social functions of metaphor though they cannot really be separated from the cognitive ones. The key social function of metaphor is its working as an ideological weapon. The fact that metaphors highlight only certain aspects of a concept while hide other ones results in a biased picture of reality. To be more specific, in spite of the fact that tsunamis and hurricanes are normal naturally occurring phenomena, newspapers provide 
us with a demonizing portrayal of them as abnormal, monstrous, angry and violent creatures, the aim of which is to attack and harm people. This biased metaphorical representation of natural catastrophes conceals the fact that the damage inflicted in these events is to a certain extent the result of a human failure. The damage in the Indian Ocean tsunami catastrophe was not caused by the natural phenomenon itself but was compounded by human-made aspects, including a destruction of protective environmental features provided by nature (Niman 2010). Furthermore, social, political and economic conditions determined the vulnerability of people to the tsunami, with the poor, the marginalized and the disempowered being affected more than the rest of the population (Gamburd and McGilvray 2010). The investigation following hurricane Katrina revealed that the blame for most of the devastation and destruction is to be ascribed to local, state and federal government:

"The Committee on Homeland Security observed that government officials failed to heed disaster warnings, made poor decisions before and after the hurricane hit, failed to provide effective leadership, and failed to develop the capacity to respond to catastrophic events." (Greene 2009: 208)

Similarly to the tsunami, those worst affected by the hurricane were the poor and the black, who did not have the means to escape and options to live anywhere other than in the Lower Ninth Ward, where most damage was inflicted (Levitt and Whitaker 2009). This was a consequence of a long history of a class-based and race discrimination in New Orleans, as Levitt and Whitaker (2009: 8) point out:

"Employment and housing discrimination remains, prejudicial zoning regulations endure, racialized bank lending and real estate practices flourish, while federally financed highways that privilege predominantly white suburbs and tax breaks for wealthier home owners facilitate this inequitable system."

Yet, all these factors are made invisible in the metaphorical portrayal of natural catastrophes used by the newspapers. Therefore, the key ideological aspect of the employment of metaphor is the concealment of politico-economic and social conditions.

As both lexical and syntactical devices realizing the three metaphor themes are consistently used throughout all the articles in the newspapers, the constructed picture of the events becomes naturalized and viewed as commonsensical. The metaphors establish vivid and memorable depictions of the tsunami and the hurricane and call forth connotations and associations which tend to remain unquestioned. Moreover, as for most people media are the only source of information about natural catastrophes, they often take the portrayal for granted. The effectiveness of metaphor stems from the fact that it naturalizes the constructed picture of reality; as Fairclough (1989: 85) points out, "ideology is most effective 
when its workings are least visible".

Talking about ideology, it might be fruitful to look at how newspapers deal with the tension between Western Enlightenment ideology of superiority of science and technology, viewing culture "as something that humans have developed over and above nature" (Dobrovol'skij and Piirainen 2005: 208), and hurricanes and tsunami as phenomena which people do not have a control over. As already stated above, newspapers employ a demonizing portrayal of the natural phenomena, which puts all the blame for the destruction on them. This might serve as a justification for human failure and failure of science and technology. At the same time, it creates a sharp division between nature and culture, which corresponds to one of the characteristic features of Western Enlightenment ideology. The division is based on a common ideological dichotomy Us versus Them, the so-called 'ideological square' (van Dijk 1996). This conceptual tool involves Positive Self-Presentation and Negative Other-Presentation with newspapers representing people as innocent victims and natural phenomena as cruel, malicious, violent monsters. The hurricane and the tsunami are thus constructed as 'outsiders' whose negative characteristics and activities are emphasized while positive ones are de-emphasized. In contrast, people are portrayed as 'insiders' whose positive characteristics and social activities are foregrounded and negative characteristics and social activities are backgrounded (Richardson 2007). The metaphor themes construct nature as people's enemy, which renders harmonious co-existence between people and nature rather difficult.

The bipolarization of the world into us (innocent, suffering people) and them (cruel and heartless natural phenomena) leads to the establishment of feelings of community and belonging among people. The representation of the events evokes sympathy towards people and antipathy towards nature, which results in readers' identification with the victims bringing about solidarity with them. It thus, in a symbolic way, knits people together into one community.

As follows from the previous discussion, another significant social function of metaphor is appeal to readers' emotions and dramatization of the situation. By transferring connotations and associations from a source conceptual domain to a target one, metaphor calls forth emotion rather than reason. Moreover, the metaphor theme of ANIMATION constitutes an aspect of a hysterical style of reporting (Fowler 1991; Chovanec 2010). The employment of hyperbolic expressions in the metaphor themes of MONSTER and WAR intensify the horror of the situation and evoke negative emotions, mostly fear, in readers. These extreme emotions "blind people to important shades of gray in situations and problemsolving discussions" (Radford 2003: 313). Furthermore, the direct appeal to people's emotions by metaphor bypasses rational appeal and thus functions as an important persuasive device (Conboy 2007: 79). In other words, without rational questioning, readers automatically accept the constructed picture of natural catastrophes given to them by the newspapers.

What is more, intensification of fear in people makes them vulnerable and aggravates their insecurity leading to their heightened willingness to be protected. 
As Altheide and Michalowski (1999: 476) reveal, "the prevalence of fear in public discourse can contribute to stances and reactive social policies that promote state control and surveillance". The police, the army and the power-holders are turned to for help and establishment of safe environment and are praised when they get control of the situation and bring order. This gives them an extra opportunity to exercise power over ordinary people resulting in the reinforcement of asymmetrical power relations. As practices that sustain unequal power relations function ideologically (Thompson 1990; Eagleton 1991; van Dijk 2008; Fairclough and Wodak 2010), evocation of fear resulting from the metaphorical discursive practice is an effective ideological tool.

\section{Conclusion}

The paper investigated the use of metaphor in newspaper articles on natural catastrophes with the focus on social and cognitive functions that metaphor performs. The analysis revealed that the newspaper representation of the 2004 Indian Ocean tsunami and 2005 Hurricane Katrina is predominantly metaphorical, drawing upon three major metaphor themes: the depiction of the natural phenomena as ANIMATE BEINGS, MONSTERS and WAR. The metaphor theme of ANIMATION is realized by lexical means ascribing to the hurricane and the tsunami a human body, sounds made by animals, and negative emotions. Animation is also established in the transitivity pattern of sentences referring to the tsunami and the hurricane, in which the natural phenomena occupy the role of an agent, implying that they act of their own volition. Hyperbolic and emotionally colored lexis are used to portray the natural phenomena as enormous, frightening and violent MONSTERS, and the WAR theme tends to be expressed in explicit similes and references to the tsunami and the hurricane as attacking, fighting and punishing people. The consistent employment of metaphorical language results in the naturalized construction of the natural phenomena as furious and heartless monsters.

Metaphor leads to the categorization of the events drawing upon frames that people are familiar with. It articulates a coherent, feasible world-view, which helps people to comprehend and make sense of natural catastrophes. It thus serves as a tool of conceptualization employed to get a better understanding of reality. Yet, the categorization process produces a black-and-white and a good-versusbad portrayal of natural catastrophes. It leads to a simplification of complex issues, hiding the causes of the events and hindering constructive action. Moreover, metaphor appeals to readers' emotions, which prevents rational problem-solving of the situation and makes people take the constructed picture of the natural phenomena for granted. By intensifying fear in people, newspapers call forth the need to be protected by those in power, resulting in the reinforcement of unequal power relations.

Demonization of natural phenomena hides the failure of the key notion of Western Enlightenment ideology - the superiority of science and technology - 
which corresponds to an anthropocentric world-view seeing mankind as dominating nature. Nevertheless, the bipolarization of the world into innocent people and violent nature maintains the sharp divide between nature and culture characteristic of Enlightenment ideology. It also contributes to the establishment of a symbolic community among people, knitting them together through the evocation of feelings of belonging and solidarity. Demonizing metaphor themes serve to justify human failure, hide politico-economic and social conditions and thus work as an effective ideological tool.

To conclude, the paper reveals on the analysis of concrete linguistic material that metaphor simultaneously performs several cognitive and social functions, which are all intertwined with each other. This multi-functionality makes metaphor a unique and very effective discursive tool to be employed in newspapers.

\section{References}

Altheide, David L. and R. Sam Michalowski (1999) 'Fear in the News: A Discourse of Control'. The Sociological Quarterly 40(3), 475-503.

Charteris-Black, Jonathan (2005) Politicians and Rhetoric: The Persuasive Power of Metaphor. New York: Palgrave Macmillan.

Chilton, Paul A. (1996) Security Metaphors: Cold War Discourse from Containment to Common House. New York: P. Lang.

Chovanec, Jan (2010) 'Legitimation through Differentiation: Discursive Construction of Jacques Le Worm Chirac as an Opponent to Military Action'. In: Okulska, Urszula and Piotr Cap (eds.) Perspectives in Politics and Discourse. Amsterdam and Philadelphia: John Benjamins, 61-81.

Conboy, Martin (2007) The Language of the News. Oxon: Routledge.

Dobrovol'skij Dmitrij and Elisabeth Piirainen (2005) Figurative Language: Cross-cultural and Cross-linguistic Perspectives. Amsterdam and Oxford: Elsevier.

Eagleton, Terry (1991) Ideology: An Introduction. London and New York: Verso.

El Refaie, Elisabeth (2001) 'Metaphors We Discriminate By: Naturalized Themes in Austrian Newspaper Articles about Asylum Seekers'. Journal of Sociolinguistics 5(3), 352-371.

Fairclough, Norman (1989) Language and Power. London and New York: Longman.

Fairclough, Norman (1995) Critical Discourse Analysis: The Critical Study of Language. London and New York: Longman.

Fairclough, Norman and Ruth Wodak (2010) 'Critical Discourse Analysis in Action' In: Coffin, Caroline, Theresa Lillis and Kieran O'Halloran (eds.) Applied Linguistics Methods: A Reader: Systemic Functional Linguistics, Critical Discourse Analysis and Ethnography. London and New York: Routledge, 98-111.

Fowler, Roger (1991) Language in the News: Discourse and Ideology in the Press. London and New York: Routledge.

Gamburd, Michele R. and Dennis McGilvray (2010) 'Introduction'. In: McGilvray, Dennis and Michele R. Gamburd (eds.) Tsunami Recovery in Sri Lanka: Ethnic and Regional Dimensions. London and New York: Routledge, 1-16.

Gibbs, Raymond W., Jr. (1994) The Poetics of Mind: Figurative Thought, Language and Understanding. Cambridge and New York: Cambridge University Press.

Goatly, Andrew (2007) Washing the Brain: Metaphor and Hidden Ideology. Amsterdam and Philadelphia: John Benjamins.

Greene, Linda S. (2009) 'Governmental Liability for the Katrina Failure'. In: Levitt, Jeremy I. and Matthew C. Whitaker (eds.) Hurricane Katrina: America's Unnatural Disaster. Lincoln: University of Nebraska Press, 206-225. 
Hiraga, Masako K. (2005) Metaphor and Iconicity: A Cognitive Approach to Analyzing Texts. Palgrave Macmillan.

Koller, Veronika (2004) 'Women and War Metaphors: "Possessive, jealous, and pugnacious?" Journal of Sociolinguistics 8(1), 3-22.

Kövecses, Zoltán (2000) Metaphor and Emotion: Language, Culture, and Body in Human Feeling. Cambridge and New York: Cambridge University Press.

Kövecses, Zoltán (2010) Metaphor: A Practical Introduction, $2^{\text {nd }}$ ed. New York: Oxford University Press.

Lakoff, George and Mark Johnson (1980) Metaphors We Live By. Chicago: University of Chicago Press.

Lakoff, George and Mark Johnson (1999) Philosophy in the Flesh: The Embodied Mind and Its Challenge to Western Thought. New York: Basic Books.

Lakoff, George and Mark Turner (1989) More than Cool Reason: A Field Guide to Poetic Metaphor. Chicago: University of Chicago Press.

Levitt, Jeremy I. and Matthew C. Whitaker (2009) 'Truth Crushed to Earth Will Rise Again'. In: Levitt, Jeremy I. and Matthew C. Whitaker (eds.) Hurricane Katrina: America's Unnatural Disaster. Lincoln: University of Nebraska Press, 1-21.

Lule, Jack (2004) 'War and Its Metaphors: News Language and the Prelude to War in Iraq, 2003'. Journalism Studies 5(2), 179-190.

Martin, Janet and Rom Harré (1982) 'Metaphor in Science'. In: Miall, David S. (ed.) Metaphor: Problems and Perspectives. Sussex: The Harvester Press, 89-105.

Musolff, Andreas (2004) Metaphor and Political Discourse: Analogical Reasoning in Debates about Europe. Palgrave Macmillan.

Niman, Michael I. (2010) 'The Political Tsunami: Not All Death and Destruction Is Natural'. In: Fuller, Linda K. (ed.) Tsunami Communication: (Inter)personal/intercultural, Media, Technical, Ethical, Philanthropic, Development, and Personal Responses. Cresskill, NJ: Hampton Press.

Ortony, Andrew (1979) 'Metaphor: A Multidimensional Problem'. In: Ortony, Andrew (ed.) Metaphor and Thought. Cambridge and New York: Cambridge University Press, 1-16.

Radford, Benjamin (2003) Media Mythmakers: How Journalists, Activists, and Advertisers Mislead Us. Amherst: Prometheus Books.

Radman, Zdravko (1997) Metaphors: Figures of the Mind. Kluwer Academic Publishers.

Richardson, John E. (2007) Analysing Newspapers: An Approach from Critical Discourse Analysis. Basingstoke: Palgrave Macmillan.

Santa Ana, Otto (1999) “"Like an Animal I Was Treated": Anti-immigrant Metaphor in US Public Discourse'. Discourse and Society 10(2), 191-224.

Semino, Elena (2008) Metaphor in Discourse. Cambridge and New York: Cambridge University Press.

Simpson, Robert H. and Herbert Riehl (1981) The Hurricane and Its Impact. Baton Rouge: Louisiana State University Press.

Thompson, John B. (1990) Ideology and Modern Culture: Critical Social Theory in the Era of Mass Communication. Cambridge: Polity Press.

Thornborrow, Joanna (1993) 'Metaphors of Security: A Comparison of Representation in Defence Discourse in Post-Cold-War France and Britain'. Discourse and Society 4(1), 99-119.

van Dijk, Teun A. (1996) Discourse, Racism and Ideology. La Laguna: Rcei Ediciones.

van Dijk, Teun A. (2008) Discourse and Power. Palgrave Macmillan.

Weiss, Gilbert and Ruth Wodak (2003) 'Introduction: Theory, Interdisciplinarity and Critical Discourse Analysis' In: Weiss, Gilbert and Ruth Wodak (eds.) Critical Discourse Analysis: Theory and Interdisciplinarity. Palgrave Macmillan, 1-32.

Wodak, Ruth (2006) 'Mediation between Discourse and Society: Assessing Cognitive Approaches in CDA'. Discourse Studies 8(1), 179-190. 
Wodak, Ruth and Michael Meyer (2009) 'Critical Discourse Analysis: History, Agenda, Theory and Methodology'. In: Wodak, Ruth and Michael Meyer (eds.) Methods of Critical Discourse Analysis, $2^{\text {nd }}$ edition. SAGE Publications, 1-33.

Dita Trčková is a PhD student at the Department of English and American Studies at Masaryk University in Brno. Her interests lie in the areas of critical discourse analysis, cognitive linguistics and anthropological linguistics. She is just completing her $\mathrm{PhD}$ thesis, which critically analyzes the representation of natural catastrophes by newspapers in Western English-speaking countries. Her previous research focused on power asymmetry in classroom discourse.

Address: Mgr. Dita Trčková, Department of English and American Studies, Masaryk University, Brno, Czech Republic. [email: tdita@mail.muni.cz] 
